\title{
Antimicrobial switch therapy in pediatric patients hospitalized by uncomplicated community-acquired pneumonia
}

\author{
Ronaldo MORALES-JUNIOR ${ }^{1}$ (D) , Anna Carlota BARRIENTOS ${ }^{3}$ (D), Raquel Maciel SCALCO ${ }^{3}$ (D) , Aline da Graça FEVEREIRO ${ }^{3}$ (D), \\ Sulim ABRAMOVICl ${ }^{3}$ D, Camila Canuto CAMPIONI ${ }^{2}$ \\ ${ }^{1}$ Instituto de Ensino e Pesquisa, Hospital Sírio-Libanês. São Paulo, SP, Brasil, ${ }^{2}$ Hospital Sírio-Libanês. Sírio-Libanês. São Paulo, SP, Brasil, \\ ${ }^{3}$ Hospital Municipal Infantil Menino Jesus. São Paulo, SP, Brasil \\ Corresponding author: Morales-Junior R, morales.ronaldo@gmail.com
}

Submitted: 20-04-2020 Resubmitted: 03-05-2020 Accepted: 04-07-2020

Peer review: blind reviewer and Maria Garbi Novaes.

\begin{abstract}
Objective: To evaluate the duration of intravenous (IV) antibiotic therapy and the practice of switch therapy to oral in the treatment of children aged 2 months to 5 years with uncomplicated severe community acquired pneumonia (CAP) in a pediatric public hospital. Methods: Retrospective, observational and cross-sectional study in which patients who started IV ampicillin treatment were selected. The patients were classified as "eligible" or "ineligible" to undergo switch therapy after 48 and 72 hours of hospitalization according to clinical criteria. Patients with length of stay $<$ or $\geq 7$ days were compared regarding demographic characteristics and antibiotic therapy, considering $p<0.05$ significant. Results: Eighty-six patients were evaluated, aged 14.4 (IQR: 10.8-22.7) months. The duration of IV therapy was 4 (IQR: 3-6) days; 56\% of patients were classified as eligible for switch therapy within $48 \mathrm{~h}$ and $74 \%$ as eligible within $72 \mathrm{~h}$. However, only 19 cases (22\%) underwent switch therapy at the appropriate time. The main reason for the transition was the accidental loss of venous access (61\%). The group with length of stay $<7$ days had a higher rate of switch and, consequently, shorter IV therapy duration $(p<0.01)$. Conclusion: The switch therapy in the first 48 to 72 hours is not routinely used in the clinical practice in patients hospitalized with CAP. The findings warn of the need for institutional initiatives on this practice, aiming at improving the quality of care with shorter IV therapy duration and impact on length of hospital stay.
\end{abstract}

Keywords: pneumonia, pediatrics, antimicrobial stewardship.

\section{Terapia sequencial antimicrobiana em pacientes pediátricos hospitalizados por pneumonia não complicada adquirida na comunidade}

\begin{abstract}
Resumo
Objetivo: Avaliar o tempo de antibioticoterapia intravenosa (IV) e a prática de terapia sequencial para via oral no tratamento de crianças entre 2 meses a 5 anos com pneumonia adquirida na comunidade (PAC) grave não complicada em um hospital público pediátrico. Métodos: Estudo retrospectivo, observacional e transversal no qual foram selecionados pacientes que iniciaram o tratamento com ampicilina IV. Os pacientes foram classificados como "elegíveis" ou "não elegíveis" para realizar terapia sequencial após 48 e 72 horas de internação de acordo com critérios clínicos. Os pacientes com tempo de internação <ou $\geq 7$ dias foram comparados em relação às características demográficas e antibioticoterapia, considerando $p<0,05$ significativo. Resultados: Foram avaliados 86 pacientes, com idade de 14,4 (IQR: 10,8-22,7) meses. O tempo da terapia IV foi 4 (IQR: 3-6) dias; 56\% dos pacientes foram classificados como elegíveis para a terapia sequencial em $48 \mathrm{~h}$ e $74 \%$ elegíveis em $72 \mathrm{~h}$. Entretanto, apenas 19 casos (22\%) foram submetidos à terapia sequencial no momento adequado. O principal motivo para a transição foi a perda acidental do acesso venoso (61\%). 0 grupo com tempo de internação $<7$ dias apresentou maior taxa de realização da terapia sequencial e, consequentemente, menor tempo de terapia IV ( $p<0,01$ ). Conclusão: A terapia sequencial nas primeiras 48 a 72 horas não é de uso rotineiro na pratica clinica nos pacientes internados com PAC. Os achados alertam para a necessidade de iniciativas institucionais sobre essa pratica, visando melhoria na qualidade assistencial com menor tempo de terapia IV e impacto no tempo de internação hospitalar.
\end{abstract}

Palavras-chave: pneumonia, pediatria, gestão de antimicrobianos. 


\section{Introduction}

Pneumonia is the leading infectious cause of death in children under the age of 5 worldwide. ${ }^{1}$ The World Health Organization (WHO) estimates that the incidence of pneumonia in children under 5 years old is 0.29 episodes per child-year, with 7 to $13 \%$ of the cases being considered severe and requiring hospitalization. ${ }^{2}$ In 2017 in Brazil, 113,905 cases of hospitalization for communityacquired pneumonia (CAP) occurred in children between 1 and 4 years old, being the main cause of hospitalization in children belonging to this age group within the scope of the Unified Health System (Sistema Único de Saúde, SUS). ${ }^{3}$

In Brazil, for outpatient treatment, amoxicillin is the first therapeutic option in children aged from two months to five years old. In cases of severe pneumonia, which require hospitalization, the Brazilian Society of Pediatrics (Sociedade Brasileira de Pediatria, SBP) recommends intravenous (IV) treatment with ampicillin or crystalline penicillin. ${ }^{4}$ Due to the problems related to the shortage of penicillin in the Brazilian market in recent years, ampicillin stands out as the medication of choice in these cases. ${ }^{5}$

Children on appropriate therapy should show signs of clinical and laboratory improvement within the first 48 to 72 hours of treatment initiation. ${ }^{6}$ Thus, for cases in which there is a need to start IV treatment, the transition from antimicrobial to oral route (OR) can be performed during this period, without impairing the treatment. ${ }^{7-10}$ In addition to clinical improvement, other criteria that should be evaluated for sequential IV therapy to OR are the following: ability to absorb oral antimicrobials, availability of an appropriate oral antimicrobial, and practical issues such as adherence to the treatment by the family or caregiver.?

In middle- and low-income countries, including Brazil, the mean hospital stay for children under 5 years of age due to pneumonia is approximately 6 days, ${ }^{11,12}$ however, when performed in a timely manner, sequential therapy can reduce this time, as it reduces the administration of intravenous drugs and facilitates hospital discharge, reducing the cost of hospitalization and contributing to the safety of the patients by reducing the adverse events inherent to IV administration. ${ }^{10,13,14}$ Several studies on the conversion of antimicrobials from IV to OR have shown significant cost reductions without compromising efficacy or safety; however, the IV therapy is often used unnecessarily and prolongedly, especially in low-income countries. ${ }^{15-19}$

In this context, a study was carried out with the objective of evaluating the current practice in relation to the IV antibiotic therapy time and sequential therapy in the treatment of children between 2 months and 5 years old hospitalized with severe uncomplicated CAP in a public pediatric hospital.

\section{Methods}

This is a retrospective, observational and cross-sectional study, carried out in a public pediatric hospital in the city of São Paulo. Patients aged between 2 and 59 months old and who used ampicillin as intravenous therapy for the treatment of CAP were selected for the study. Patients who were diagnosed with a discarded CAP during hospitalization, who had chronic heart disease or lung disease, were immuno-suppressed, and those who presented complications (pleural effusion, empyema, pneumatocele, necrotizing pneumonia, and lung abscesses) were excluded. Patients with a hospital stay of less than 48 hours were also excluded.

The capture of cases was done through an electronic report of prescriptions of hospitalized patients who received ampicillin in the period from November 2017 to October 2018. The clinical data of patients were collected from medical records and prescriptions for the period of hospitalization.

Patients were classified as "eligible" or "not eligible" to undergo sequential IV antimicrobial therapy to OR after 48 and 72 hours of hospitalization. The eligibility criteria were defined as follows: clinical improvement (absence of chest indrawing, without tachypnea and afebrile for 24 hours) and oral acceptance of fluids (without vomits or severe diarrhea and without restriction of OR fluid intake). Afebrile patients with axillary temperature $\leq 37.8$ were considered. To assess respiratory rate, age-based reference values were used according to the American Heart Association. ${ }^{20}$

The results of the continuous variables data are represented by median and interquartile ranges (IQR), while the categorical data are represented by absolute (n) and relative (\%) frequencies. The Mann-Whitney test was used to assess possible discrimination amoong patients with a length of stay $<$ or $\geq 7$ days in relation to demographic characteristics and to the antibiotic therapy performed. For numerical variables, the categorical data were analyzed using Pearson's Chi-square test and a value of $p<0.05$ was considered statistically significant.

The research project was approved by the ethics committee of the Menino Jesus Hospital, which provided the data for the research (CAAE 15342019.6.0000.5639), exempt from the need to apply the Free and Informed Consent Form (FICF) to parents or legal guardians of the participants because it is a retrospective observational study in which the research subjects will not be identified.

\section{Results}

A total of 340 patients used ampicillin as the therapy of choice for CAP and were initially evaluated. 33 patients with chronic heart disease and/or pulmonary or immuno-suppressed were excluded, 30 patients developed complications and 86 patients had a diagnosis of pneumonia away during hospitalization. 57 patients with a hospital stay of less than 48 hours were also excluded and 48 patients had no information available on electronic medical records. At the end, 86 patients were analyzed in the study, Table 1. Most of the patients (44\%) were between 1 and 2 years old at the time of admission, followed by patients aged between 2 months and 1 year old (27\%).

A statistically significant difference was observed in the duration of the IV therapy between the groups with a length of stay $<$ or $\geq 7$ days ( 4 days versus 7 days, $p<0.01$ ), as well as in the antimicrobial OR time ( 7 days versus 4 days, $p<0.01$ ).

Sequential IV antimicrobial therapy to OR was performed in 41 (48\%) patients. Among these patients, the median time of intravenous antimicrobials administered until the time of transition was 96 (IQR: 72-120) hours, being lower in the group with a hospital stay $<7$ days ( 72 hours) compared to the group with a hospitalization time $\geq 7$ days (120 hours), with statistical significance $(p<0.01)$. The total duration of the antibiotic therapy was 10 (IQR: 10-12) days and a 5 to 7 day regimen was performed on 13 patients (15\%). 
Table 1. Patient information regarding eligibility for sequential oral treatment and association of the variables with length of stay less than or greater than/ equal to 7 days, São Paulo, 2019.

\begin{tabular}{|c|c|c|c|c|}
\hline \multirow[b]{2}{*}{ Data } & \multirow{2}{*}{$\begin{array}{c}\text { All } \\
N=86\end{array}$} & \multicolumn{2}{|c|}{ Hospital stay² } & \multirow[b]{2}{*}{ p-value } \\
\hline & & $\begin{array}{c}<7 \text { days } \\
N=57\end{array}$ & $\begin{array}{c}\geq 7 \text { days } \\
N=29\end{array}$ & \\
\hline \multicolumn{5}{|l|}{ Sociodemographic } \\
\hline Age (months old) Median $\left(\mathrm{P}_{25} ; \mathrm{P}_{75}\right)$ & $14.4(10.8 ; 22.7)$ & $17.6(12.2 ; 26.5)$ & $12.1(6 ; 16.7)$ & $0.039^{2}$ \\
\hline Male gender ${ }^{1} \mathrm{n}(\%)$ & $46(53)$ & $31(23)$ & $15(17)$ & $0.815^{3}$ \\
\hline \multicolumn{5}{|l|}{ Characteristics of the treatment } \\
\hline Total treatment time (days) Median $\left(\mathrm{P}_{25} ; \mathrm{P}_{75}\right)$ & $6(4 ; 7)$ & $10(9 ; 12)$ & $10(19 ; 12.5)$ & $0.58^{2}$ \\
\hline Intravenous ampicillin time (days) Median $\left(\mathrm{P}_{25} ; \mathrm{P}_{75}\right)$ & $4(3 ; 6)$ & $4(3 ; 6)$ & $7(7 ; 10)$ & $<0.01^{2}$ \\
\hline Oral antimicrobial time (days) Median $\left(\mathrm{P}_{25} ; \mathrm{P}_{75}\right)$ & $6(4 ; 8)$ & $7(5 ; 8)$ & $4(2 ; 6)$ & $>0.01^{2}$ \\
\hline Eligible for sequential therapy after 48 h of hospitalization ${ }^{1} \mathrm{n}(\%)$ & $48(56.0)$ & $35(40.7)$ & $13(15.1)$ & $0.14^{3}$ \\
\hline Eligible for sequential therapy after $72 \mathrm{~h}$ of hospitalization ${ }^{1} \mathrm{n}(\%)$ & $64(74.0)$ & $46(53.0)$ & $18(20.9)$ & $0.06^{3}$ \\
\hline Did not perform IV-OR transition ${ }^{1}$ n (\%) & $45(52.0)$ & $37(43.0)$ & $8(9.3)$ & $0.001^{3}$ \\
\hline
\end{tabular}

${ }^{1}$ Dichotomous variable, results presented if only one of the categories. ${ }^{2}$ Mann-Whitney's test; ${ }^{3}$ Chi-square test; IV: Intravenous; OR: Oral Route

The eligibility criteria for sequential therapy were applied to all the patients, 48 (55.8\%) were classified as eligible at $48 \mathrm{~h}$, and $64(74 \%)$ at $72 \mathrm{~h}$. Sequential therapy was performed in a timely manner, that is, at the time when the patient was considered eligible, in 19 patients (22\%),

The reasons reported in the medical records for performing IV-OR sequential therapy in patients on whom it was performed, were the following: patient accidentally lost venous access (61\%) and patient in clinical improvement (4.9\%). In $34.1 \%$ of the cases, the reason was not reported in the medical record.

\section{Discussion}

The results reveal that the duration of the IV treatment in children hospitalized with CAP was longer than the recommended time of 48 to 72 hours and that, for most of the patients, sequential antimicrobial therapy was not performed during hospitalization. Even among the cases in which sequential therapy was performed, the data suggest the needlessly prolonged use of the IV therapy, since in only $22 \%$ of the patients did the transition take place at the appropriate time.

The comparison between groups with a length of stay $<$ or $\geq 7$ days indicated a statistically significant relationship between the duration of the IV antimicrobial treatment and length of hospital stay, as the group with shorter length of stay also had a shorter length of antimicrobial IV.

The findings were similar to those found by Wei T. Sze and Mei C. Kong (2018) in a multicenter study, in which the mean IV therapy time was $4.05 \pm 2.81$ days and only $24 \%$ of the patients received sequential therapy at the time they were considered eligible. In this study, the authors also identified that the majority of the patients remained on IV therapy until the time of hospital discharge and then conducted a strategy for implementing sequential therapy that significantly reduced the duration of IV therapy, length of stay and treatment costs. ${ }^{21}$ Another study conducted with the aim of exploring the current practice of sequential therapy in hospitalized patients found that only $20.9 \%$ the patients received sequential therapy in a timely manner, although $68 \%$ of the patients who started IV antimicrobials could be transitioned to OR. ${ }^{22}$
The World Health Organization (WHO) reports that the excessive use of intravenous drugs, when oral formulations would be more appropriate, is one of the main factors for the irrational use of medications worldwide. ${ }^{23}$ It is common among health professionals to believe that the bioavailability of intravenous drugs is always greater than that of their oral equivalent and that the patient will have better outcomes and a lower rate of re-infection with an intravenous treatment. ${ }^{24}$ The fact, however, is that the antimicrobials generally used in the treatment of pneumonia, as well as many other antimicrobials used in different conditions, have excellent bioavailability when administered by OR with similar outcomes and less risk for the patient. ${ }^{21}$ Other barriers described in the literature for carrying out appropriate sequential therapy mainly include misconceptions, practical considerations, reduced pharmacy staff, and organizational factors. $^{22,25,26}$ Therefore, it is likely that most of these barriers can be reduced through educational interventions and structural organizational changes.

Our study identified that the main reason for performing sequential IV therapy to OR was accidental loss of venous access, evidencing the non-use of specific clinical criteria for the transition. The Infectious Diseases Society of America (IDSA) recommends that institutions introduce a systematic plan for switching from IV antimicrobial therapy to OR based on the specific conditions of each patient and on the characteristics of the microorganisms prevalent in the region. ${ }^{27}$ Therefore, each hospital must implement its guideline in order to direct pharmaceutical interventions towards an ideal sequential therapy, as interventions of this type are generally well accepted by the medical staff., 728 In addition, the institutional guidelines work as an educational strategy and contemplate one of the key objectives of the WHO for the control of antimicrobial resistance as they promote the development of knowledge and skills of the professionals involved. ${ }^{29}$

Regarding the total treatment time observed in the study, it was noted that the patients received antimicrobials according to a traditional 10 to 14 day approach, although two recent systematic reviews and the current $\mathrm{WHO}$ recommendation suggest that courses of 3 to 7 days of antimicrobials are sufficient for the treatment of uncomplicated CAP. ${ }^{7,30,31}$ Prolonged exposure to antimicrobials can promote the development or acquisition of organisms resistant to antimicrobials and be associated with serious adverse reactions. ${ }^{32}$ 
A limitation of this study is that it is a retrospective observational study; therefore, for the collection of clinical data, only medical records were considered and the physicians were not directly asked about their approach in relation to the length of the therapy, and there may be loss of information. In addition, it was not possible to investigate practical factors to consider eligibility for sequential therapy, such as the parents' adherence to the treatment. Other criteria that justify the differences found in the length of hospital stay between patients were also not evaluated.

\section{Conclusion}

The study identified that children hospitalized with CAP often receive intravenous antimicrobials for a prolonged period of time and that, despite its proven benefits, sequential IV therapy to OR has not been implemented in the routine clinical practice for these patients so far.

The results found alert to the need for new institutional and medical awareness initiatives regarding this practice, aiming to improve quality of care and patient safety, with a reduction in the time of IV therapy, impact on costs and hospitalization time.

\section{Funding source}

The research did not receive financing for its realization.

\section{Collaborators}

MJR: Main author of the paper. Responsible for preparing and writing the article, and for data collection. BAC: Contributed to formulating the research question that originated the paper, and substantially contributed with suggestions incorporated into the paper. SRM: Contributed in data collection and in writing the article. FAG: Contributed in writing the article. AS: Contributed in writing the article. CCC: Work advisor. Assisted in the structuring and writing of the article, as well as contributed substantially with suggestions incorporated into the work.

\section{Acknowledgments}

To all the professionals working the Pharmacy of the Menino Jesus Hospital for all their support and for providing an adequate environment to develop this work.

\section{Conflict of interests statement}

The authors declare that there are no conflicts of interest regarding this article.

\section{References}

1. Liu L, Oza S, Hogan D, et al. Global, regional, and national causes of under-5 mortality in 2000-15: an updated systematic analysis with implications for the Sustainable Development Goals. The Lancet. 2016;388(10063):3027-35.

2. Rudan I, Boschi PC, Biloglav Z, et al. Epidemiology and etiology of childhood pneumonia. Bull World Health Organ.

\section{8;86(5):408-16}

3. Ministério da Saúde. Morbidade Hospitalar do SUS- por local de residência - Brasil. Available in:http://tabnet.datasus.gov. br/cgi/tabcgi.exe?sih/cnv/nrbr.def. Accessed on April 20, 2020.

4. Sociedade Brasileira de Pediatria. Pneumonia adquirida na Comunidade na Infância. Available in https://www.sbp.com. br/fileadmin/user_upload/Pneumologia_-_20981d-DC_Pneumonia_adquirida na comunidade-ok.pdf 8. Accessed on April 20, 2020.

5. Rosa $M B$, Reis $A M M$, Perini $E$, et al. Drug shortage: a public health problem. Cad. de Saúde Pública. 2016;32(10):e00086916.

6. Bradley JS, Byington CL, Shah SS, et al. The Management of Community-Acquired Pneumonia in Infants and Children Older Than 3 Months of Age: Clinical Practice Guidelines by the Pediatric Infectious Diseases Society and the Infectious Diseases Society of America. Clin Infect Dis. 2011;53(7):e2576.

7. McMullan BJ, Andresen D, Blyth CC, et al. Antibiotic duration and timing of the switch from intravenous to oral route for bacterial infections in children: systematic review and guidelines. Lancet Infect Dis. 2016;16(8):e139-52.

8. Agweyu A, Gathara D, Oliwa J, et al. Oral Amoxicillin Versus Benzyl Penicillin for Severe Pneumonia Among Kenyan Children: A Pragmatic Randomized Controlled Noninferiority Trial. Clin Infect Dis. 2015;60(8):1216-24.

9. Rodriguez-Pardo D, Pigrau C, Campany D, et al. Effectiveness of sequential intravenous-to-oral antibiotic switch therapy in hospitalized patients with gram-positive infection: the SEQUENCE cohort study. EurJ Clin Microbiol \& Infect Dis. 2016;35(8):1269-76.

10. Sallach-Ruma, R, Nieman, J, Sankaranarayanan, et al. Correlates and Economic and Clinical Outcomes of an Adult IV to PO Antimicrobial Conversion Program at an Academic Medical Center in Midwest United States. J Pharm Pract. 2015;28(3):238-248.

11. Zhang S, Sammon PM, King I, et al. Cost of management of severe pneumonia in young children: systematic analysis. J Glob Health. 2016;6(1):010408.

12. Veras TN, Sandim G, Mundim K, et al. Perfil epidemiológico de pacientes pediátricos internados com pneumonia. Scientia Medica. 20120;20(4):277-81.

13. Mertz D, Koller M, Haller P, et al. Outcomes of early switching from intravenous to oral antibiotics on medical wards. J Antimicrob Chemother. 2009;64(1):188-99.

14. Waagsb $\varnothing$ B, Sund $\varnothing y$ A, Paulsen EQ. Reduction of unnecessary i.v. antibiotic days using general criteria for antibiotic switch. Scand J Infect Dis. 2008;40(6-7):468-73.

15. Zhang L, Hu P. Cost-effectiveness analysis of oral versus intravenous drip infusion of levofloxacin in the treatment of acute lower respiratory tract infection in Chinese elderly patients. Clin Interv Aging. 2017;(12):673-678

16. Davis SL, Delgado G, McKinnon PS. Pharmacoeconomic considerations associated with the use of intravenous-to-oral 
moxifloxacin for community-acquired pneumonia. Clin Infect Dis. 2005;41 Suppl 2:S136-143.

17. Kuti JL, Le TN, Nightingale CH, Nicolau DP, et al. Pharmacoeconomics of a pharmacist-managed program for automatically converting levofloxacin route from i.v. to oral. Am J Health Syst Pharm. 2002;59(22):2209-15.

18. Boyles TH, Whitelaw A, Bamford C, et al. Antibiotic stewardship ward rounds and a dedicated prescription chart reduce antibiotic consumption and pharmacy costs without affecting inpatient mortality or re-admission rates. PLOS ONE. 2013;8(12):e79747.

19. Fox ER, Beckwith MC, Tyler LS. Pharmacy-Administered IV to Oral Therapeutic Interchange Program: Development, Implementation, and Cost-Assessment. Hospital Pharmacy, 2003;38(5), 444-452.

20. Allan RC, Marc DB, Leon C, et al. Part 12: Pediatric Advanced Life Support: 2015 American Heart Association Guidelines Update for Cardiopulmonary Resuscitation and Emergency Cardiov.Circulation. 2015;132:S526-S542

21. Sze WT, Kong MC. Impact of printed antimicrobial stewardship recommendations on early intravenous to oral antibiotics switch practice in district hospitals. Pharm Pract (Granada). 2018;16(2):855.

22. BeyeneBerha A, Kassie GM. Current Practice and Barriers to an Early Antimicrobial Conversion from Intravenous to Oral among Hospitalized Patients at Jimma University Specialized Hospital: Prospective Observational Study. Interdiscip Perspect Infect Dis. 2019:7847354

23. WHO. WHO | The Pursuit of Responsible Use of Medicines: Sharing and Learning from Country Experiences. Disponíve em: http://www.who.int/medicines/publications/responsible use/en/. Acesso em 15 de janeiro de 2020

24. Fischer MA, Solomon DH, Teich JM, et al. Conversion from intravenous to oral medications: assessment of a computerized intervention for hospitalized patients. Arch Intern Med. 2003;163(21):2585-9.

25. Engel MF, Postma DF, Hulscher MEJL, et al. Barriers to an early switch from intravenous to oral antibiotic therapy in hospitalised patients with CAP. Eur Respir J. 2013;41(1):123-30.

26. Banko H, Goldwater SH, Adams E. Smoothing the Path for Intravenous (IV) to Oral (PO) Conversion: Where Have We Come in 11 Years? Hospital Pharmacy. 2009 44(11), 959-967.

27. Dellit TH, Owens RC, McGowan JE, et al. Infectious Diseases Society of America and the Society for Healthcare Epidemiology of America guidelines for developing an institutional program to enhance antimicrobial stewardship. Clin Infect Dis. 2007;44(2):159-77.

28. Currius MV, Barcons IA, Santanach LG, et al. CP-177 Switch from intravenous to oral therapy: A prospective study. Eur J Hosp Pharm. 2016;23:A78.

29. WHO. WHO | Global action plan on antimicrobial resistance [Internet]. World Health Organization. Available in: http:// www.who.int/antimicrobial-resistance/publications/global-action-plan/en. Accessed on January 15, 2020.

30. López AJ, Rodriguez BR, Redondo SJ, et al. Short-course versus long-course therapy of the same antibiotic for community-acquired pneumonia in adolescent and adult outpatients. Cochrane Database Syst Rev. 2018;2018(9).

31. Revised WHO Classification and Treatment of Pneumonia in Children at Health Facilities: Evidence Summaries. Geneva: World Health Organization. Available in : http://www.ncbi. nlm.nih.gov/books/NBK264162. Accessed on January 15, 2020.

32. Aliberti S, Blasi F, Zanaboni AM, et al. Duration of antibiotic therapy in hospitalised patients with community-acquired pneumonia. Eur Respir J. 2010;36(1):128-34. 